\title{
ATRIBUTOS MICROBIOLÓGICOS E ESTRUTURA DE COMUNIDADES BACTERIA- NAS COMO INDICADORES DA QUALIDADE DO SOLO EM PLANTIOS FLORES- TAIS NA MATA ATLÂNTICA
}

\author{
MICROBIOLOGICAL ATTRIBUTES AND STRUCTURE OF BACTERIAL COMMUNITIES AS IN- \\ DICATORS OF SOIL QUALITY IN FOREST PLANTATIONS IN THE ATLANTIC FOREST
}

\author{
Andressa Danielli Canei ${ }^{1}$ Anabel González Hernández ${ }^{2}$ Diana M. L. Morales (In Memoriam) ${ }^{1}$ \\ Emanuela P. da Silva ${ }^{3}$ Luiz F. Souza ${ }^{4}$ Arcangelo Loss ${ }^{5}$ Cledimar Rogério Lourenzi ${ }^{5}$ Maurício \\ Sedrez dos Reis ${ }^{5}$ Cláudio R. F. S. Soares ${ }^{6}$
}

\section{RESUMO}

No Brasil, a fim de minimizar o impacto da exploração de espécies arbóreas para fins comerciais em florestas nativas, plantios florestais têm sido implantados, majoritariamente, com espécies exóticas. A avaliação de tais cultivos quanto ao impacto proporcionado ao ambiente em atributos que podem garantir sua produtividade tem recebido maior atenção nos últimos anos, enquadrando-se neste contexto, o estudo de atributos microbiológicos. Deste modo, este trabalho teve como objetivo avaliar os impactos de plantios florestais de Pinus sp. (pinus) e Araucaria angustifolia (araucária) sobre os atributos microbiológicos do solo e a estrutura da comunidade bacteriana, que podem funcionar como indicadores da qualidade do solo. Para tanto, foram coletadas amostras de solo em três áreas na Floresta Nacional de Três Barras (FLONA), Santa Catarina (SC): uma área de floresta nativa (F), uma área de reflorestamento com araucária (A) e outra com pinus $(\mathrm{P})$. Posteriormente, foi realizada a caracterização química e física do solo, além das análises microbiológicas: respiração basal, atividade da enzima $\beta$-glucosidase e fosfatase ácida, , e análise da estrutura de comunidades bacterianas PCR-DGGE. Os solos das três áreas de estudo apresentaram baixa fertilidade, destacando a importância dos micro-organismos para a manutenção desses ambientes. A atividade da enzima $\beta$-glucosidase e da fosfatase ácida foi maior nas áreas $\mathrm{F}$ e $\mathrm{A}$, sugerindo maior presença de micro-organismos importantes para a ciclagem de nutrientes. A análise da estrutura da comunidade bacteriana demonstrou que há uma baixa divergência entre as áreas de pinus e araucária. Pode-se concluir que, com base nos atributos microbiológicos e na estrutura de comunidades bacterianas do solo, em plantios florestais da Mata Atlântica, a araucária destaca-se como melhor alternativa para reflorestamento, visando a manutenção da qualidade do solo.

Palavras-chave: Araucaria angustifolia; atividade enzimática; micro-organismos; reflorestamento.

1 Bióloga, MSc., Doutoranda do Programa de Pós-graduação em Recursos Genéticos Vegetais, Universidade Federal de Santa Catarina, Campus Trindade, CEP 88040-900, Florianópolis (SC), Brasil. andressacanei@gmail.com

2 Microbióloga, MSc., Doutoranda do Programa de Pós-graduação em Recursos Genéticos Vegetais, Universidade Federal de Santa Catarina, Campus Trindade, CEP 88040-900, Florianópolis (SC), Brasil. anabelgonzalezher@ yahoo.es

3 Engenheira Agrônoma, MSc., Doutoranda do Programa de Pós-graduação em Recursos Genéticos Vegetais, Universidade Federal de Santa Catarina, Campus Trindade, CEP 88040-900, Florianópolis (SC), Brasil. manu_ pilles@hotmail.com

4 Estudante de Agronomia, Universidade Federal de Santa Catarina, Campus Trindade, CEP 88040-900, Florianópolis (SC), Brasil. luiz.fernando.souza@grad.ufsc.br

5 Engenheiro Agrônomo, Dr., Professor do Centro de Ciências Agrárias, Universidade Federal de Santa Catarina, Campus Itacurubi, CEP 88034-000, Florianópolis (SC), Brasil. arcangeloloss@yahoo.com.br / lourenzicr@gmail. com / msedrez@gmail.com

6 Engenheiro Agrônomo, Dr., Professor do Centro de Ciências Biológicas, Universidade Federal de Santa Catarina, Campus Trindade, CEP 88040-900, Florianópolis (SC), Brasil. crfsoares@gmail.com

Recebido para publicação em 22/12/2016 e aceito em 05/09/2017

Ci. Fl., v. 28, n. 4, out. - dez., 2018 


\section{ABSTRACT}

In Brazil, in order to minimize the impact of native forest exploitation for commercial purposes, forest plantations have been implemented mainly with exotic species. The evaluation of these crops as to the environmental impact on attributes that can guarantee their productivity has received more attention in the last years, and in this context, the study of microbiological attributes. This paper assesses the impact of Pinus sp. (pinus) and Araucaria angustifolia (araucária) forest plantations on the microbiological soil attributes and the structure of bacterial communities, which can act as indicators of soil quality. Soil samples have been collected on three areas of the National Forest of Três Barras, in Santa Catarina (SC) state: one area of native forest $(\mathrm{F})$, one area of reforestation with araucária (A) and one area of reforestation with pinus (P). Later on, the soil was chemically and physically characterized and the microbiological analyses were performed, as basal respiration, $\beta$-glucosidase and fosfatase enzymatic activity and analysis of bacterial community structure by PCR-DGGE. Low fertility was presented on all three soils collected, highlighting the importance of microorganisms in order to maintain this environment. The $\beta$-glucosidase and fosfatase enzymatic activity were higher on the areas $\mathrm{F}$ and $\mathrm{A}$, suggesting a higher presence of important microorganisms for nutrients cycling. The analysis of the bacteria community structure resulted in low distinction between the pinus and the araucária areas. This paper presents that based on the microbiological attributes and structure of bacterial communities of soil, in forest plantations of the Atlantic Forest, it is possible to conclude that araucária is the best alternative for reforestation, aiming the maintenance of soil quality.

Keywords: Araucaria angustifolia; enzymatic activity; microorganisms; reforestation.

\section{INTRODUÇÃO}

A Mata Atlântica é um importante bioma brasileiro caracterizado pela alta diversidade de espécies e alto grau de endemismo. Entretanto, hoje se apresenta como um mosaico composto por poucas áreas relativamente extensas, principalmente nas regiões sul e sudeste e um volume bem maior de áreas fragmentadas em diversos estágios de degradação. A Mata Atlântica é considerada um dos 34 hotspots de biodiversidade do mundo sendo uma área prioritária para conservação (LAGOS; MULLER, 2009). Deste modo, os fragmentos florestais assumem fundamental importância para a preservação desse bioma.

Dentre as fitofisionomias do Bioma Mata Atlântica, a Floresta Ombrófila Mista (FOM) é uma das mais ameaçadas (MEDEIROS; SAVI; BRITO, 2005). Nesse ambiente destaca-se a presença de Araucaria angustifolia, que é uma espécie nativa intensamente explorada, ao ponto de exaustão de suas reservas naturais no final da década de 80 e que atualmente encontra-se enquadrada na categoria de vulnerável à extinção. Devido à qualidade da sua madeira para os mais diversos fins, como fabricação de serrados, laminados e indústria moveleira, além de utilização na indústria de papel, plantios comerciais têm sido realizados (ASSOCIAÇÃO BRASILEIRA DE PRODUTORES DE FLORESTAS PLANTADAS, 2013). Entretanto, apesar de sua importância, a área de cultivos comerciais é relativamente pequena e concentrada nos estados do Paraná e Santa Catarina. Segundo a IBÁ (INDÚSTRIA BRASILEIRA DE ÁRVORES, 2016), 11.038 hectares foram plantados no ano de 2015. Além da importância comercial madeireira (FERRARI, 2011), $A$. angustifolia estabelece importantes relações ecológicas com a fauna e produz uma semente comestível (pinhão), utilizada na alimentação humana (INOUE; RODENJAN; KUNIJOSKI, 1984; CARVALHO, 1994; THOMÉ, 1995; SILVA; SEDREZ, 2009).

Apesar da importância da araucária, há pouco conhecimento das suas exigências silviculturais, especificamente das técnicas de plantio que favorecem o desenvolvimento das mudas no campo. Outro fator importante que incide sobre a dificuldade do reflorestamento para fins comerciais é a seleção inadequada dos locais a serem reflorestados, uma vez que essa espécie é exigente quanto às condições edáficas (SILVA et al., 2001). Desse modo, são necessários estudos relacionados às condições edafoclimáticas que possam favorecer o sucesso no reflorestamento com araucária, uma vez que é uma espécie nativa com importantes serviços ecossistêmicos.

Por outro lado, espécies exóticas como Pinus e Eucalyptus encontraram no Brasil condições eda- 
foclimáticas que permitem um excelente crescimento nos mais diversos locais, sendo os principais gêneros utilizados em florestas plantadas. Esses gêneros correspondem a cerca de 20 e $72 \%$ da área plantada, respectivamente (INDÚSTRIA BRASILEIRA DE ÁRVORES, 2016), somando 7,2 milhões de hectares em 2015. O plantio de Pinus e Eucalyptus tem seu ponto inicial marcado pelo advento do incentivo fiscal, uma diretriz estratégica dos anos 60 e 70 (SIQUEIRA, 2003). Na região sul do Brasil, encontram-se um total de 2 milhões de hectares, correspondendo a $26 \%$ da área total plantada com esses gêneros no país (INDÚSTRIA BRASILEIRA DE ÁRVORES, 2016). Tal fato demonstra o importante papel do pinus na cadeia produtiva da madeira, com destaque na economia nacional (BACHA, 2008), fornecendo matéria-prima para os setores madeireiro, moveleiro e de papel e celulose (MENDES, 2005; VASQUEZ et al., 2007).

As mudanças no ambiente proporcionadas pelo plantio de espécies exóticas, como Pinus e Eucalyptus têm sido cada vez mais estudadas (ZILLER, 2000; CHAER; TÓTOLA, 2007; ZALBA; CUEVAS; BOÓ, 2008). O interesse de avaliar os atributos do solo, expandiu-se devido à crescente preocupação em determinar as consequências das práticas de manejo sobre a qualidade do solo em relação à sustentabilidade das funções do ecossistema florestal, além da produtividade da planta (SCHOENHOLTZ; VAN MIEGROET; BURGER, 2000).

Até recentemente, os atributos químicos e físicos do solo eram os mais considerados na avaliação dos impactos e da capacidade produtiva dos plantios florestais, devido à intima relação com o desenvolvimento vegetal (SCHOENHOLTZ; VAN MIEGROET; BURGER, 2000). Atualmente, maior atenção vem sendo dada ao estudo de atributos microbiológicos (BARETTA et al., 2005; CHAER; TÓTOLA, 2007; SILVA et al., 2007). Nesse contexto, os micro-organismos podem aumentar a capacidade produtiva de solos por serem responsáveis principalmente pela constante ciclagem de nutrientes e na disponibilidade de elementos como carbono, nitrogênio, fósforo e enxofre, auxiliando no estabelecimento das espécies vegetais (MOREIRA; SIQUIERA, 2006). Diferentemente dos indicadores físicos e químicos, os atributos microbiológicos permitem a obtenção de respostas rápidas às mudanças na qualidade do solo. Algumas vezes, mudanças na população e atividade microbiana podem ocasionar alterações nas propriedades químicas e físicas, refletindo um claro sinal de melhoria ou degradação do solo (ARAÚJO; MONTEIRO, 2007). Vários estudos demonstraram que as propriedades biológicas e bioquímicas do solo, tais como a respiração basal, a atividade enzimática, o nitrogênio da biomassa microbiana, o carbono da biomassa microbiana e diversidade microbiana podem funcionar como indicadores sensíveis, possibilitando sua utilização no monitoramento de possíveis modificações ambientais (DORAN; PARKIN, 1994; SANTANA; BAHIA FILHO, 1998; ARAÚJO; MONTEIRO, 2007; ARAÚJO et al., 2012; CARVALHO; MOREIRA; CARDOSO, 2012; KHEYRODIN; GHAZVINIAN; TAHERIAN, 2012; BALOTA et al., 2014; PAREDES JUNIOR; PORTILHO; MERCANTE, 2015; FRANZLUEBBERS, 2016; VASCONCELLOS et al., 2016; ZANINETTI; MOREIRA; MORAES, 2016).

Este trabalho teve como objetivo avaliar os impactos de plantios florestais de pinus e araucária sobre a qualidade do solo, utilizando como indicadores os atributos microbiológicos e a estrutura de comunidades bacterianas.

\section{MATERIAL E MÉTODO}

\section{Área de estudo}

Amostras de solo foram coletadas em novembro de 2015 na Floresta Nacional de Três Barras-SC, sendo amostradas três áreas distintas: uma área de floresta ombrófila mista em estágio avançado de regeneração (F), uma área de reflorestamento com Araucaria angustifolia (A) e uma área com reflorestamento de Pinus sp. (P).

Em cada área foi estabelecido um grid de $100 \times 100$ metros, com cinco pontos amostrais georreferenciados (Figura 1). Em cada local de amostragem foi selecionado um ponto central e coletadas quatro subamostras em um diâmetro de quatro metros e outras quatro amostras em oito metros, totalizando oito subamostras por ponto amostral. As amostras de solo foram coletadas na camada de $0-20 \mathrm{~cm}$, sendo as amostras destinadas às análises de atividade microbiana acondicionadas em sacos plásticos e transportadas sob refrigeração até o laboratório de Microbiologia do Solo da Universidade Federal de Santa Catarina, onde foram armazenadas a $4{ }^{\circ} \mathrm{C}$. Subamostras destinadas à análise molecular foram armazenadas a $-80{ }^{\circ} \mathrm{C}$. 
As amostras destinadas às análises químicas e físicas do solo foram transportadas à temperatura ambiente e posteriormente secas ao ar.

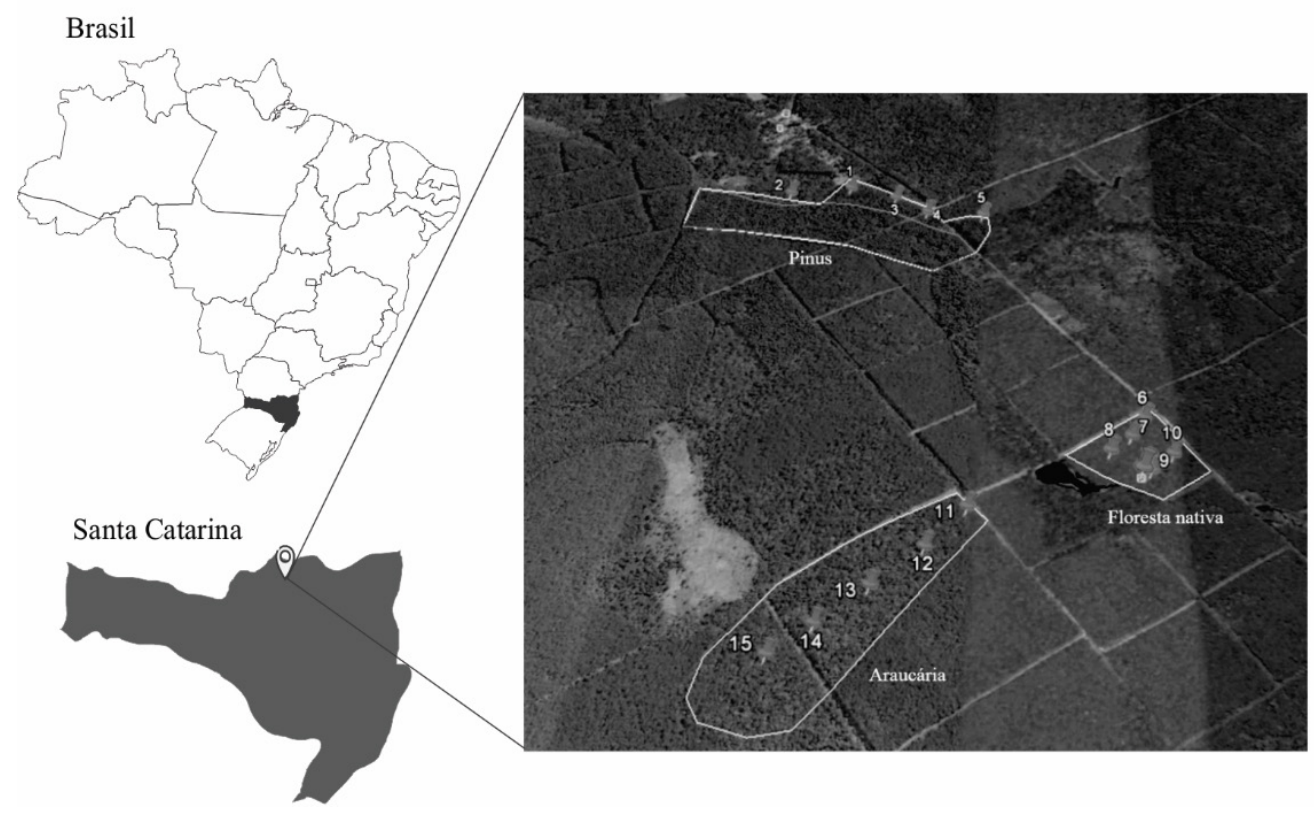

FIGURA1: Área de coleta das amostras de solo em três áreas na Floresta Nacional de Três Barras-SC. Números 1 a 5 referem-se às repetições da área $\mathrm{P} ; 6$ a 10 referente a F; 11 a 15 referente a área $\mathrm{A}$.

FIGURE 1: Collection area of soil samples on three areas at the National Forest of Três Barras, SC state. Numbers 1 to 5 refer to the repetitions of area P; 6 to 10 referring to F; 11 to 15 referring to area A.

\section{Análises físicas e químicas do solo}

Foram realizadas análises granulométricas do solo das três áreas de coleta, seguindo a metodologia da Embrapa (1997). A análise química dos elementos fósforo $(\mathrm{P})$, cálcio $(\mathrm{Ca})$, carbono orgânico $\left(\mathrm{C}_{\mathrm{org}}\right)$, alumínio ( $\mathrm{Al})$, magnésio $(\mathrm{Mg})$, potássio $(\mathrm{K})$, além da $\mathrm{CTC}$ efetiva e $\mathrm{pH}\left(\mathrm{H}_{2} \mathrm{O}\right)$, foram realizadas seguindo as metodologias propostas por Tedesco et al. (1995).

\section{Atributos microbiológicos do solo}

Para determinar a respiração basal, três subamostras de $50 \mathrm{~g}$ de solo foram acondicionadas em recipientes hermeticamente fechados com capacidade para $500 \mathrm{~mL}$, juntamente com um béquer contendo $20 \mathrm{~mL}$ de $\mathrm{NaOH} 0,2 \mathrm{~mol} \mathrm{~L}^{-1}$. Após um período de incubação de seis dias, o $\mathrm{NaOH}$ residual foi titulado com $\mathrm{HCl}$ 0,2 $\mathrm{mol} \mathrm{L}^{-1}$ (ALEF, 1995) sendo o resultado expresso em mg C-CO $\mathrm{kg}_{2}$ solo seco ${ }^{-1} \mathrm{~h}^{-1}$.

A atividade das enzimas $\beta$-glucosidase e fosfatase ácida foi quantificada por meio da quantidade de $p$-nitrofenol liberado após a hidrólise do substrato correspondente. No caso da $\beta$-glucosidase, 1,0 grama de solo foi suspenso em $p$-nitrofenil ß-D-glicopiranosideo em solução tampão universal modificada (MUB pH 6,0), com incubação a $37{ }^{\circ} \mathrm{C}$ durante uma hora. Em seguida, a reação foi interrompida pela adição de $\mathrm{CaCl}_{2}$ 0,5 mol L-1. A mistura foi filtrada e a absorbância do extrato foi medida a $410 \mathrm{~nm}$ (TABATABAI, 1982; EIVAZI; TABATABAI, 1988). Para a fosfatase ácida, 1,0 grama de solo foi misturado com p-nitrofenil fosfato em solução tampão universal modificada (MUB pH 6,5) e incubado a $37^{\circ} \mathrm{C}$ durante uma hora. Posteriormente, a reação foi interrompida mediante adição de $0,5 \mathrm{~mol} \mathrm{~L}^{-1} \mathrm{CaCl}_{2}$ e $0,5 \mathrm{~mol} \mathrm{~L}^{-1} \mathrm{NaOH}$. Essa mistura foi filtrada e a absorbância do extrato foi medida em espectrofotômetro UV-visível a $410 \mathrm{~nm}$ (TABATABAI; BREMNER, 1969; EIVAZI; TABATABAI, 1977). 


\section{Análises das comunidades microbianas por PCR-DGGE}

Inicialmente, procedeu-se a extração de DNA total do solo utilizando o Kit Power Soil (MobioLaboratories Inc., Carlsbad, CA, USA) seguindo as orientações do fabricante. Em seguida, realizou-se a análise do perfil da comunidade bacteriana das áreas de estudo a partir de fragmentos da região V3 do gene rDNA 16S que foram amplificados utilizando-se os iniciadores BA338fGC (5 GCC CGC CGC GCG CGG CGG GCG GGG CAC GGA CTC CGG GAG GCA GCA 3`) e UN518r (5`ATTA CCG CGG CTG CTG G 3').

Os amplicons assim obtidos foram separados mediante uso de eletroforese em gel com gradiente desnaturante (DGGE). A eletroforese foi realizada em gel com $8 \%(\mathrm{~m} / \mathrm{V})$ de acrilamida:bisacrilamida $(37,5: 1, \mathrm{~m}: \mathrm{m})$, contendo um gradiente de $15 \%$ a $55 \%$ de formamida e ureia (ØVREÅS et al., 1997) a 200 V e $60{ }^{\circ} \mathrm{C}$ constantes, utilizando-se um sistema "DCode" (BioRad, Hercules, CA, USA) e tampão 1X TAE buffer durante 200 minutos. O DNA foi corado com Sybr Green (Life Technologies, São Paulo, Brasil) e a aquisição das imagens dos géis foi feita em fotodocumentador Gel Logic 200 Imaging System (Carestream Health, New York, USA). Os perfis de bandas obtidos foram analisados com o programa Bionumerics 7.10 (BioSystematica, Wales, UK).

\section{Análises estatísticas}

Os dados de atividade enzimática e respiração basal foram testados quando a normalidade e a homogeneidade das variâncias empregando os testes de Shapiro-Wilk e Cochran, respectivamente. Posteriormente submetidos à análise de variância utilizando delineamento inteiramente casualizado e as médias separadas pelo teste Tukey a 5\% empregando o programa estatístico Sisvar (FERREIRA, 2011). Os dados da atividade microbiológica, juntamente com os atributos químicos (com maior correlação e relevância), foram submetidos ao coeficiente de correlação de Pearson e à Análise de Componentes Principais (ACP). As variáveis foram estandardizadas e a análise realizada no software R (R CORE TEAM, 2014).

Os perfis de bandas das comunidades de bactérias em cada fitofisionomia gerados por PCR-DGGE foram comparados mediante teste de ANOSIM com o coeficiente de similaridade de Jaccard, utilizando o Programa Past3.

\section{RESULTADOS E DISCUSSÃo}

\section{Análises físicas e químicas do solo}

A análise granulométrica do solo (Tabela 1) indica que as áreas $\mathrm{F}$ e A apresentam a mesma classe textural (muito argilosa), diferindo da área $\mathrm{P}$ que apresenta textura argilossiltosa.

Segundo Brady (1989), a fração de argila regula as propriedades físicas do solo, agindo como centro de atividade, sendo que, ao redor dessas partículas ocorrem reações químicas e trocas de substâncias nutritivas. A textura argilosa apresenta elevada superfície específica e propriedades peculiares como o tipo de carga (+/-), sendo predominantemente eletronegativas (LOPES; GUILHERME, 1992). Tal fato influencia a disponibilidade de nutrientes e é importante na interação com os micro-organismos, afetando a sobrevivência, sucessão e interação entre os organismos, além de sua atividade (MOREIRA; SIQUEIRA, 2006). 
TABELA 1: Análises físico-químicas do solo das três áreas de estudo na FLONA de Três Barras-SC.

TABLE 1: Physical-chemical analyzes of the soil from the three study areas at FLONA of Três Barras, SC state.

\begin{tabular}{cccc}
\hline Atributos físico-químicos & Floresta nativa & Araucária & Pinus \\
\hline Classe textural & muito argilosa & muito argilosa & argilossiltosa \\
Teor de Argila (\%) & 61,8 & 66,3 & 50,8 \\
$\mathrm{P}\left(\mathrm{mg} \mathrm{dm}^{-3}\right)$ & $0,48 \pm 0,10$ & $0,62 \pm 0,06$ & $1,87 \pm 0,81$ \\
$\mathrm{~K}\left(\mathrm{cmol}_{\mathrm{c}} \mathrm{dm}^{-3}\right)$ & $0,11 \pm 0,01$ & $0,13 \pm 0,05$ & $0,15 \pm 0,00$ \\
$\mathrm{Ca}\left(\mathrm{cmol}_{\mathrm{c}} \mathrm{dm}^{-3}\right)$ & $0,050 \pm 0,05$ & $0,010 \pm 0,00$ & $0,056 \pm 0,07$ \\
$\mathrm{Mg}\left(\mathrm{cmol}_{\mathrm{c}} \mathrm{dm}^{-3}\right)$ & $0,014 \pm 0,01$ & $0,004 \pm 0,00$ & $0,014 \pm 0,01$ \\
$\mathrm{Al}\left(\mathrm{cmol}_{\mathrm{c}} \mathrm{dm}^{-3}\right)$ & $7,4 \pm 1,97$ & $15,64 \pm 6,17$ & $17,88 \pm 1,77$ \\
$\mathrm{C}$ org $\left(\mathrm{g} \mathrm{kg}^{-1}\right)$ & $12,64 \pm 3,11$ & $22,48 \pm 0,39$ & $24,66 \pm 1,82$ \\
$\mathrm{pH}_{\mathrm{H} 20}$ & $4,43 \pm 0,19$ & $4,32 \pm 0,10$ & $4,14 \pm 0,57$ \\
$\mathrm{H}+\mathrm{Al}\left(\mathrm{cmol}_{\mathrm{c}} \mathrm{dm}^{-3}\right)$ & $17,50 \pm 8,67$ & $24,31 \pm 2,71$ & $30,20 \pm 15,06$ \\
$\mathrm{CTCefetiva}\left(\mathrm{cmol}^{\mathrm{c}} \mathrm{dm}^{-3}\right)$ & $12,64 \pm 3,11$ & $15,78 \pm 1,98$ & $19,81 \pm 4,70$ \\
\hline
\end{tabular}

Em que: $\mathrm{P}=$ fósforo, $\mathrm{K}=$ potássio, $\mathrm{Ca}=$ cálcio, $\mathrm{Mg}=$ magnésio, $\mathrm{Al}=$ alumínio, $\mathrm{C}_{\text {org }}$ = carbono orgânico.

Em relação às análises químicas do solo (Tabela 1) é possível verificar que todas as áreas avaliadas apresentam um pH muito ácido, alta saturação por alumínio, baixo teor de matéria orgânica, e teor muito baixo de fósforo, evidenciando uma baixa fertilidade. Segundo Herrera et al. (1978), florestas sob solos de baixa fertilidade retornam menor quantidade de material formador de serapilheira em relação a solos férteis. Entretanto, desenvolvem mecanismos alternativos para maximizar a absorção de nutrientes, como a simbiose com micro-organismos do solo, por exemplo, com fungos micorrízicos e bactérias fixadoras de nitrogênio. Moreira-Souza et al. (2003) demonstraram a importância dessa relação simbiótica com a araucária, assim como relataram cerca de 23 espécies de fungos micorrízicos arbusculares (FMAs) associados a mesma. Neroni e Cardoso (2007) isolaram e sequenciaram parcialmente o gene 16S rRNA de bactérias provenientes de amostras de solo de áreas com araucária, as quais se enquadraram em oito grupos fenotípicos, sendo: Pseudomonas, Burkholderia, Yersinia, Xhantomonas, Janthinobacterium, Brevundimonas, Brucella e Novosphingobium.

$\mathrm{O}$ teor de carbono foi menor na área de floresta nativa se comparado às outras duas áreas. Segundo Caldeira et al. (2002), espécies exóticas como o Pinus sp., apresentam uma decomposição relativamente lenta da serapilheira e consequente imobilização dos nutrientes, levando, assim, a um alto teor de carbono no solo. Watzlawick et al. (2002) observaram que em locais com grande predomínio de Araucaria angustifolia, a quantidade de serapilheira acumulada era maior que em outros locais da FOM que possuíam poucos indivíduos de araucária.

\section{Análises microbiológicas}

A respiração basal representa o $\mathrm{CO}_{2}$ produzido pela biomassa microbiana durante os processos de decomposição e mineralização da matéria orgânica adicionada ao solo, sendo um dos indicadores microbiológicos mais utilizados para avaliar a atividade da microbiota heterotrófica do solo (MOREIRA; SIQUEIRA, 2006). Altos valores de respiração basal podem indicar maior atividade metabólica dos micro-organismos, em que o fluxo de $\mathrm{CO}_{2}$ está relacionado à intensidade dos processos catabólicos (COUTO et al., 2013). Na Figura 2 é possível verificar que as áreas F e A apresentaram incrementos médios de 113\% em relação à área P. Esses resultados vão ao encontro daqueles descritos por Baretta, Baretta e Cardoso (2008), que encontraram diferenças na respiração basal de uma área de plantio de pinus e uma área de mata 
nativa na FOM. Souza (2005) também encontrou valores de respiração maior em área de FOM e de reflorestamento com araucária em relação a uma área de pinus durante o verão. Resultados semelhantes foram obtidos em um trabalho realizado por Vinhal-Freitas et al. (2013), no qual se comparou uma área nativa do Cerrado com uma área de pinus. No entanto, em outro trabalho realizado pelo mesmo grupo (BARETTA, 2007) foram verificados valores maiores para respiração basal na mata nativa (FOM), em relação às áreas de reflorestamento com araucária.

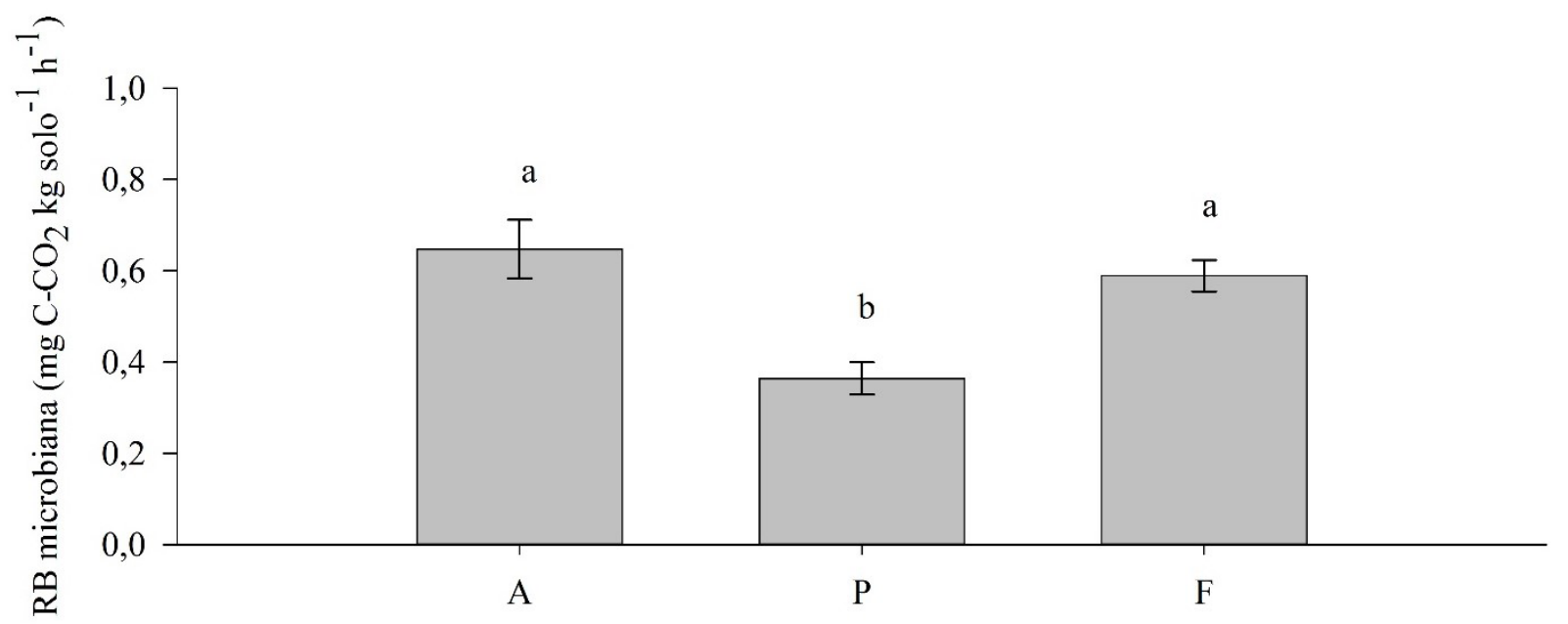

FIGURA 2: Respiração basal (RB) nas três áreas de estudo - reflorestamento com araucária (A), reflorestamento com pinus $(\mathrm{P})$ e floresta nativa $(\mathrm{F})$. Barras indicam erro padrão da média.

FIGURE 2: Basal respiration (RB) in the three study areas - reforestation with araucaria (A), reforestation with pinus $(\mathrm{P})$ and native forest $(\mathrm{F})$. Bars indicate mean standard error.

Em relação à atividade da enzima $\beta$-glucosidase, os dados obtidos demonstraram que as áreas $\mathrm{A} e$ $\mathrm{F}$ apresentaram incrementos médios de $346 \%$ quando comparadas à área $\mathrm{P}$ (Figura 3). A maior atividade da enzima $\beta$-glucosidase nessas áreas indica que existe maior quantidade de material facilmente decomponível que servirá como fonte de nutrientes para as comunidades microbianas, tornando-o disponível para as plantas por meio da mineralização. Vinhal-Freitas et al. (2013) comparando uma área de mata nativa do Cerrado com uma área de pinus, encontraram valores para $\beta$-glucosidase na mata nativa muito maiores em relação à área de pinus, corroborando os resultados apresentados neste trabalho. 

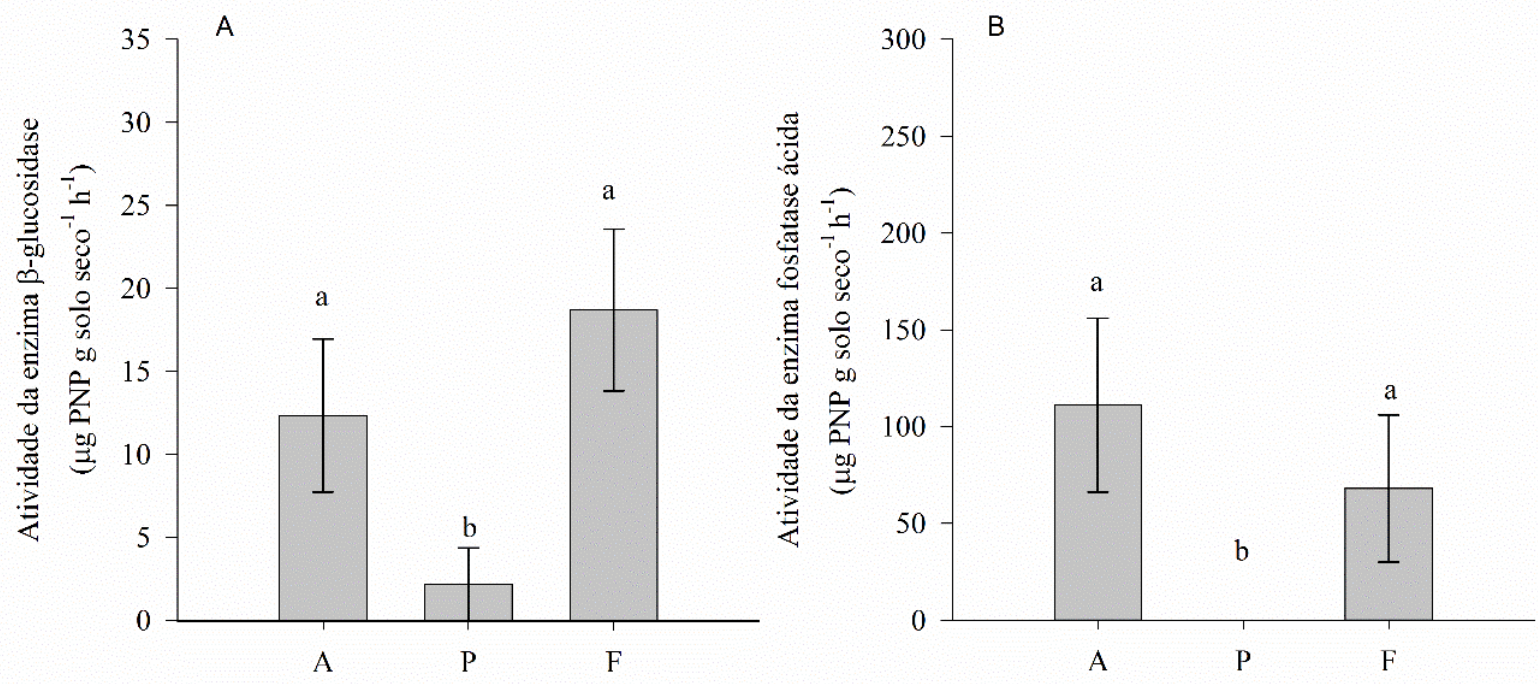

FIGURA 3: Atividade da enzima $\beta$-glucosidase (A) e fosfatase ácida (B) nas três áreas de estudo - reflorestamento com araucária (A), reflorestamento com pinus (P) e floresta nativa (F). Barras indicam o erro padrão da média. PNP (p-nitrofenil fosfato).

FIGURE 3: Enzymatic activity of $\beta$-glucosidase (A) and acid phosphatase (B) in the three study areas - reforestation with araucaria (A), reforestation with pinus (P), and native forest (F). Bars indicate mean standard error. PNP (p-nitrophenyl phosphate).

O mesmo comportamento foi observado na atividade da fosfatase ácida, sendo maior nas áreas A e F, não diferindo estatisticamente entre si. Entretanto, não foi verificada atividade dessa enzima na área $P$. A presença de uma elevada atividade da fosfatase ácida nas áreas $\mathrm{F}$ e A sugere a adaptação das espécies à carência de fósforo. Nsabimana, Haynes e Wallis (2004) encontraram baixos níveis de atividade enzimática em uma área de reflorestamento com pinus, na África do Sul. Os autores atribuíram esse resultado aos efeitos inibitórios exercidos por compostos fenólicos presentes nas acículas, comportamento semelhante ao observado no presente estudo. Silva et al. (2009) em um estudo no qual compararam uma área nativa do Bioma Cerrado com uma área de plantio de pinus (Pinus tecunumanii) também observaram baixa atividade da enzima fosfatase ácida na área de pinus. Como pode-se observar, em relação aos atributos microbiológicos analisados, o reflorestamento com araucária se mostrou menos impactante sobre a atividade microbiana do solo que o reflorestamento com pinus, não diferindo da floresta nativa. Assim é possível considerar a araucária como a melhor alternativa de uso em programas de reflorestamento, em relação ao pinus.

A atividade da enzima $\beta$-glucosidase apresentou correlação negativa com os teores de fósforo $\left(\mathrm{R}^{2}=\right.$ $-0,591)$ e carbono $\left(\mathrm{R}^{2}=-0,652\right)$ do solo. Entretanto, a atividade da enzima fosfatase ácida não apresentou correlação significativa com nenhum dos elementos mensurados (Tabela 2). Segundo Eivazi e Tabatabai (1988), a atividade da enzima $\beta$-glucosidase apresenta correlação significativa com a matéria orgânica do solo, atuando tanto na hidrólise da celobiose como também de oligossacarídeos liberando açúcares que serão fontes de energia para os micro-organismos. Dado o baixo teor de carbono encontrado nas três áreas, o carbono que a enzima mineraliza é rapidamente imobilizado pela microbiota. Já o coeficiente negativo observado para o fósforo pode estar relacionado com a importância desse nutriente para o metabolismo microbiano, o que levaria a uma maior demanda de fósforo pelos micro-organismos. 
TABELA 2: Coeficiente de correlação de Pearson $(\mathrm{n}=15)$ entre os atributos químicos e biológicos do solo das três áreas de coleta.

TABLE 2: Pearson correlation coefficient $(n=15)$ between the chemical and biological attributes of the soil of the three collect areas.

\begin{tabular}{cccc}
\hline & Atributos & Microbiológicos & \\
\cline { 2 - 4 } Atributos químicos & Fosfatase ácida & $\beta$-glucosidase & Respiração basal \\
\hline P & $-0,412$ & $-0,591 *$ & $-0,471$ \\
K & $-0,239$ & $-0,197$ & $-0,012$ \\
$\mathrm{Ca}$ & $-0,302$ & $-0,085$ & $-0,048$ \\
$\mathrm{Mg}$ & $-0,215$ & $-0,153$ & $-0,095$ \\
$\mathrm{C}_{\text {org }}$ & $-0,652^{*}$ & $-0,652^{*}$ & $-0,224$ \\
\hline
\end{tabular}

Em que: $\mathrm{P}=$ fósforo, $\mathrm{K}$ = potássio, $\mathrm{Ca}$ = cálcio, $\mathrm{Mg}$ = magnésio, $\mathrm{C}_{\text {org }}$ = carbono orgânico.

A fim de se visualizar como os atributos microbiológicos variam nas diferentes áreas, bem como os químicos que possuem maior correlação com a atividade microbiana, realizou-se a ACP (Figura 4). Na ACP foi possível verificar que os dois principais eixos são capazes de explicar $79 \%$ da variação existente nesses locais. Verifica-se que o grupo formado pelas amostras da área P se diferencia principalmente do grupo formado pelas amostras da área $\mathrm{F}$ em relação ao teor de carbono e fósforo no solo. Pode-se observar também que os grupos formados pelas áreas de $\mathrm{F}$ e $\mathrm{A}$ estão associados à maior atividade enzimática ( $\beta$-glucosidase, fosfatase ácida e respiração basal). Entretanto, há amostras pertencentes às áreas $\mathrm{F}$ e A que não apresentam uma clara separação quanto à predominância de determinada atividade microbiana.

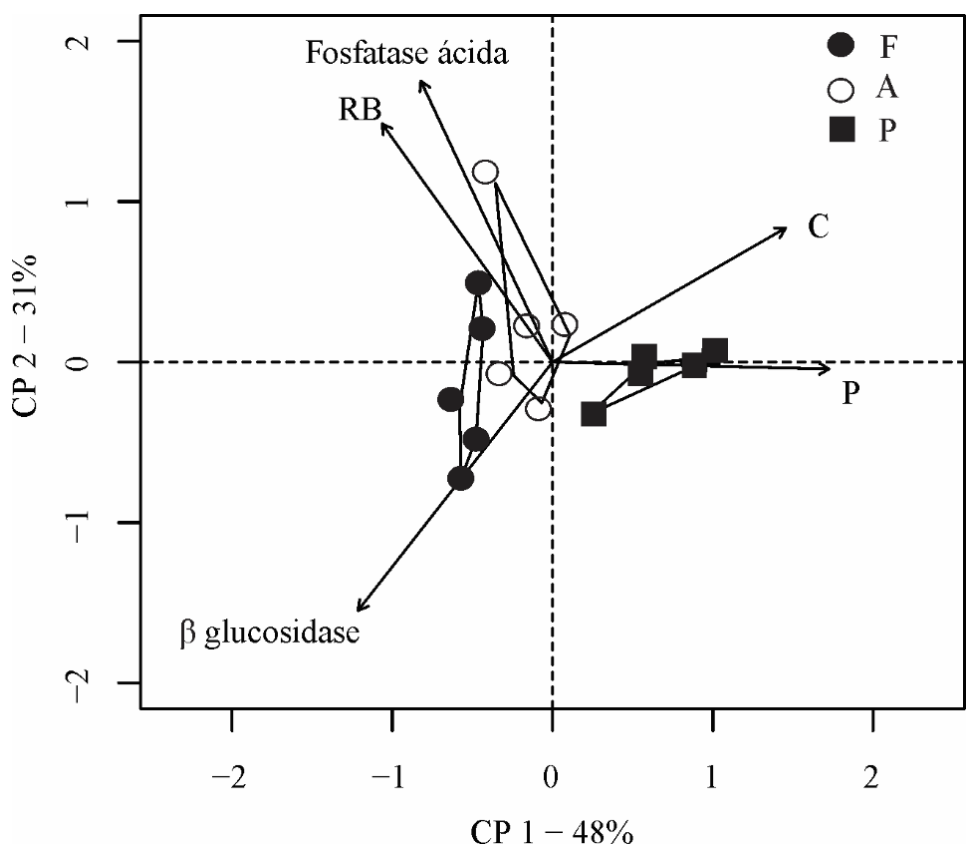

Em que: $(\mathrm{A})=$ reflorestamento com araucária; $(\mathrm{P})=$ reflorestamento com pinus $(\mathrm{P}) ;(\mathrm{F})=$ floresta nativa; $\mathrm{RB}=$ Respiração basal microbiana; $\mathrm{C}=$ carbono; $\mathrm{P}=$ fósforo.

FIGURA 4: Diagrama de ordenação baseado nos eixos 1 e 2 obtido por meio da Análise de Componentes Principais representando $79 \%$ da variabilidade original dos atributos nas três áreas de estudo.

FIGURE 4: Ordination diagram based in axes 1 and 2 obtained through Principal Component Analysis representing $79 \%$ of the original variability of the attributes in the three study areas. 


\section{Análise da estrutura de comunidades bacterianas por PCR-DGGE}

Os resultados da análise de ANOSIM podem ser observados na Tabela 3. O valor de $\mathrm{R}$ global indica que há diferença entre as amostras provenientes das três áreas. Já os valores de $\mathrm{R}$ pairwise revelou que a diferença das comunidades bacterianas observadas nas áreas de araucária e pinus foi menor que a observada entre essas e a área de floresta.

TABELA 3: Resultado do teste de ANOSIM por pareamento (Pairwise) baseado nos perfis de amplicons da região V3 de bactérias.

TABLE 3: Result by pairing ANOSIM test (Pairwise) based on the amplicons profiles from the bacteria region V3.

\begin{tabular}{cccc}
\hline \multirow{2}{*}{ Áreas } & \multicolumn{3}{c}{ Teste de Pairwise* } \\
\cline { 2 - 4 } & Floresta & Araucária & Pinus \\
\hline Floresta & - & - & - \\
Araucária & $0,952^{*}$ & - & - \\
Pinus & $0,924^{*}$ & $0,364^{*}$ & - \\
\hline
\end{tabular}

*R Global $=0,8018 ; P<0.001$ com correção de Bonferroni.

As semelhanças entre as comunidades bacterianas nas áreas de pinus e araucária podem estar relacionadas com a proximidade filogenética dessas duas espécies, uma vez que ambas pertencem à mesma ordem Pinales, selecionando assim os grupos bacterianos ao seu redor. Embora a araucária seja uma espécie presente na floresta nativa, sua densidade é menor e há uma expressiva ocorrência de outras espécies vegetais, explicando os valores de R tão próximos de 1, indicando uma alta divergência da floresta nativa. Baretta (2007) também constatou diferenças significativas pelo teste de Pairwise na estrutura da comunidade bacteriana entre uma área de floresta nativa e uma área de reflorestamento com araucária.

Ao se compararem os dados de atividade microbiana junto aos obtidos na análise de estrutura de comunidades bacterianas, pode ser verificado que mesmo existindo uma alta divergência entre as comunidades presentes nas áreas de A e F, há níveis semelhantes de atividade microbiana, sugerindo uma alta redundância funcional entre os grupos de micro-organismos presentes em ambas as áreas (ALLISON; MARTINY, 2008).

\section{CONCLUSÕES}

Áreas de plantios com pinus apresentaram menor atividade microbiológica do solo com base na respiração basal e atividade das enzimas $\beta$-glucosidase e da fosfatase ácida. Com isso, o reflorestamento com a araucária representa a melhor alternativa para a manutenção dos atributos microbiológicos do solo em plantios florestais da Mata Atlântica. Embora tenham sido encontradas semelhanças na atividade microbiana entre as áreas com plantio de araucária e floresta nativa, foram observadas diferenças na estrutura da comunidade bacteriana entre esses locais.

\section{REFERÊNCIAS}

ALEF, K. Estimation of soil respiration. In: ALEF, K.; NANNIPIERI, P. (Eds.). Methods in applied soil microbiology and biochemistry. London: Academic Press, 1995. p. 214-219.

ALLISON, S. D.; MARTINY, J. B. Resistance, resilience, and redundancy in microbial communities. Proceedings of the National Academy of Sciences, New York, v. 105, n. 1, p. 11512-11519, aug. 2008. ARAÚJO, A. S. F.; MONTEIRO, R. T. R. Indicadores biológicos de qualidade do solo. Bioscience Journal, Uberlândia, v. 23, n. 3, p. 66-75, jul. 2007.

ARAÚJO, E. A. et al. Qualidade do solo: conceitos, indicadores e avaliação. Revista Brasileira de Tecnologia Aplicadas nas Ciências Agrárias, Guarapuava, v. 5, n. 1, p. 187-206, jan. 2012. 
ASSOCIAÇÃO BRASILEIRA DE PRODUTORES DE FLORESTAS PLANTADAS. Anuário estatístico da ABRAF 2013 ano base 2012. Brasília: ABRAF, 2013.

BACHA, C. J. C. Análise da evolução do reflorestamento no Brasil. Revista de Economia Agrícola, São Paulo, v. 55, n. 1, p. 5-24, jul. 2008.

BALOTA, E. L. et al. Soil microbial properties after long-term swine slurry application to conventional and no-tillage systems in Brazil. Science of the Total Environment, Barcelona, v. 490, p. 397-404, aug. 2014. BARETTA, C. R. D. M. Diversidade microbiana em solos sob florestas de Araucaria angustifolia. 2007. 184 f. Tese (Doutorado) - Escola Superior de Agricultura "Luiz de Queiroz", Piracicaba, 2007.

BARETTA, D.; BARETTA, C. R. D. M.; CARDOSO, E. J. B. N. Análise multivariada de atributos microbiológicos e químicos do solo em florestas com Araucaria angustifolia. Revista Brasileira de Ciência do Solo, Viçosa, MG, v. 32, n esp, p. 2683-2691, out. 2008.

BARETTA, D. et al. Efeito do monocultivo de Pinus e da queima do campo nativo em atributos biológicos do solo no Planalto Sul-Catarinense. Revista Brasileira de Ciência do Solo, Viçosa, MG, v. 29, n. 5 , p. 715-724, sept. 2005.

BRADY, N. C. Natureza e propriedades dos solos. 7. ed. Rio de Janeiro: Freitas Bastos, 1989. 898 p.

CALDEIRA, M. V. W. et al. Carbono orgânico em solos florestais. In: SANQUETTA, C. R. et al. (Ed.). As florestas e o carbono. Curitiba: Imprensa Universitária da UFPR, 2002. p. 191-213.

CARVALHO, P. E. R. Espécies florestais brasileiras: recomendações silviculturais, potencialidades e uso da madeira. Colombo: EMBRAPA; CNPF; SPI, 1994. 640 p.

CARVALHO, F.; MOREIRA, F. M. S.; CARDOSO, E. J. B. Chemical and biochemical properties of Araucaria angustifolia (Bert.) Ktze. forest soils in the state of São Paulo. Revista Brasileira de Ciência do Solo, Lavras, v. 36, n. 4, p. 1189-1202, jul. 2012.

CHAER, G. M.; TÓTOLA, M. R. Impacto do manejo de resíduos orgânicos durante a reforma de plantios de eucalipto sobre indicadores de qualidade do solo. Revista Brasileira de Ciência do Solo, Viçosa, MG, v. 31, n. 6, p. 1381-1396, nov. 2007.

COUTO, R. R. et al. Microbiological and chemical attributes of a Hapludalf soil with swine manure fertilization. Pesquisa Agropecuária Brasileira, Brasília, v. 48, n. 7, p. 774-782, jul. 2013.

DORAN, J. W.; PARKIN, T. B. Defining and assessing soil quality. In: DORAN, J. W. et al. (Ed.). Defining soil quality for a sustainable environment. Madison: SSSA, 1994. p. 1-20.

EIVAZI, F.; TABATABAI, M. A. Glucosidases and galactosidases in soils. Soil Biology and Biochemistry, Leicestershire, v. 20, n. 5, p. 601-606, 1988.

EIVAZI, F.; TABATABAI, M. A. Phosphatases in soils. Soil Biology and Biochemistry, Leicestershire, v. 9, n. 3, p. 167-172, 1977.

EMBRAPA. Manual de métodos de análise de solo. 2. ed. Rio de Janeiro: EMBRAPA, 1997. 230 p.

FERRARI, A. M. W. A utilização de madeira nativa para exploração comercial sustentável no setor de construção civil: a possibilidade da Araucaria angustifolia. 2011. 189 f. Dissertação (Mestrado) Universidade Federal do Paraná, Curitiba, 2011.

FERREIRA, D. F. Sisvar: a computer statistical analysis system. Ciência e Agrotecnologia, Lavras, v. 35, n. 6, p. 1039-1042, nov. 2011.

FRANZLUEBBERS, A. J. Should soil testing services measure soil biological activity? Agricultural \& Environmental Letters, Madison, v. 1, n. 1, feb. 2016.

HERRERA, R. et al. Amazon ecosystems. Their structure and functioning with particular emphasis on nutrients. Interciencia, Caracas, v. 3, n. 4, p. 223-231, jul. 1978.

INDÚSTRIA BRASILEIRA DE ÁRVORES. Relatório IBÁ 2016. Brasília: IBÁ, 2016.

INOUE, M. T.; RODENJAN, C. V.; KUNIJOSKI, Y. S. Projeto madeira de Paraná. Curitiba, FUPEF, 1984. $260 \mathrm{p}$.

KHEYRODIN, H.; GHAZVINIAN, K.; TAHERIAN, M. Tillage and manure effect on soil microbial biomass and respiration, and on enzyme activities. African Journal of Biotechnology, [s. 1.], v. 11, n. 81, p. 14652-14659, oct. 2012.

LAGOS, A. R.; MULLER, B. L. A. Hotspot brasileiro - Mata Atlântica. Saúde \& Ambiente em Revista, Duque de Caxias, v. 2, n. 2, jul. 2009.

LOPES, A. S.; GUILHERME, L. A. G. Solos sob cerrado: manejo da fertilidade para a produção 
agropecuária. São Paulo: ANDA, 1992. 49 p.

MEDEIROS, J. D.; SAVI, M.; BRITO, B. F. A. Seleção de áreas para criação de Unidades de Conservação na Floresta Ombrófila Mista. Biotemas, Florianópolis, v. 18, n. 2, p. 33-50, mar. 2005.

MENDES, J. B. Estratégias e mecanismos financeiros para florestas plantadas. 2005. $72 \mathrm{f}$. Monografia (MBA em Gestão Empresarial) - Fundação Getúlio Vargas, Curitiba, 2005.

MOREIRA, F. M. S.; SIQUEIRA, J. O. Microbiologia e bioquímica do solo: 2. ed. Lavras: UFLA, 2006. MOREIRA-SOUZA, M. et al. Arbuscular mycorrhizal fungi associated with Araucaria angustifolia (Bert.) O. Ktze. Mycorrhiza, Oregon, v. 13, n. 4, p. 211-215, aug. 2003.

NERONI, R. F.; CARDOSO, E. J. B. N. Occurrence of diazotrophic bacteria in Araucaria angustifolia. Scientia Agricola, Piracicaba, v. 64, n. 3, p. 303-304, may 2007.

NSABIMANA, D.; HAYNES, R. J.; WALLIS, F. M. Size, activity and catabolic diversity of the soil microbial biomass as affected by land use. Applied Soil Ecology, Firenze, v. 26, n. 2, p. 81-92, jun. 2004. ØVREÅS, L. et al. Distribution of bacterioplankton in meromictic Lake Saelenvannet, as determined by denaturing gradient gel electrophoresis of PCR-amplified gene fragments coding for 16S rRNA. Applied and environmental microbiology, New York, v. 63, n. 9, p. 3367-3373, sept. 1997.

PAREDES JUNIOR, F. P. P.; PORTILHO, I. I. R.; MERCANTE, F. M. Microbiological attributes of the soil under cultivation of sugarcane with and without burning straw. Semina: Ciências Agrárias, Londrina, v. 36, n. 1, p. 151-164, jan. 2015.

R CORE TEAM. R: A language and environment for statistical computing. R Foundation for Statistical Computing, Vienna, Austria, 2014.

SANTANA, D. P.; BAHIA FILHO, A. F. C. Soil quality and agricultural sustainability in the Brazilian Cerrado. In: WORLD CONGRESS OF SOIL SCIENCE, 1998, Montpellier. Proceedings... Montpellier: ISSS, 1998.

SCHOENHOLTZ, S. H.; VAN MIEGROET, H.; BURGER, J. A. A review of chemical and physical properties as indicators of forest soil quality: challenges and opportunities. Forest Ecology and Management, Eveleigh, v. 138, p. 335-356, nov. 2000.

SILVA, C. V.; SEDREZ, M. R. Produção de pinhão na região de Caçador, SC: aspectos da obtenção e sua Importância para comunidades locais. Ciência Florestal, Santa Maria, v. 19, n. 4, p. 363-374, out. 2009.

SILVA, H. D. et al. Recomendação de solos para Araucaria angustifolia com base nas suas propriedades físicas e químicas. Boletim de Pesquisa Florestal, Colombo, v. 43, p. 61-74, jul. 2001.

SILVA, L. G. et al. Atributos físicos, químicos e biológicos de um Latossolo de cerrado em plantio de espécies florestais. Pesquisa Agropecuária Brasileira, Brasília, v. 44, n. 6, p. 613-620, jun. 2009.

SILVA, M. B. et al. Atributos biológicos do solo sob influência da cobertura vegetal e do sistema de manejo. Pesquisa Agropecuária Brasileira, Brasília, v. 42, n. 12, p. 1755-1761, dez. 2007.

SIQUEIRA, J. P. D. Os conflitos institucionais da gestão florestal no Brasil: um benchmarking entre os principais produtores florestais internacionais. 2003. $182 \mathrm{f}$. Tese (Doutorado) - Universidade Federal do Paraná, Curitiba, 2003.

SOUZA, I. M. Z. Carbono e nitrogênio da biomassa microbiana do solo em áreas reflorestadas comparadas ao campo e a mata nativa no planalto dos Campos Gerais, SC. 2005. 61 f. Dissertação (Mestrado) - Universidade Federal de Santa Catarina, Florianópolis, 2005.

TABAtABAi, M. A. Soil enzyme. In: PAGE, A. L.; MILLER, E. M.; KEENEY, D. R. (Ed.). Methods of Soil Analysis, Part 2, Chemical and Microbiological Properties. Madison: American Society of Agronomy, 1982. p. 903-947.

TABATABAI, M. A.; BREMENER, J. M. Use of p-nitrophenyl phosphate for assay of soil phosphatase activity. Soil Biology and Biochemistry, Leicestershire, v. 1, p. 301-307, nov. 1969.

TEDESCO, M. J. et al. Análises de solo, plantas e outros materiais. Porto Alegre: UFRGS, 1995. v. $2.176 \mathrm{p}$.

VASQUEZ, A. G. et al. Uma síntese da contribuição do gênero Pinus para o desenvolvimento sustentável no sul do Brasil. Floresta, Curitiba, v. 37, n. 3, set. 2007.

THOMÉ, N. Ciclo da Madeira: história da devastação da Floresta da Araucária e do desenvolvimento da indústria da madeira em Caçador e na região do Contestado no século XX. Caçador: Universal, 1995. 206 p. VASCONCELLOS, R. L. F. et al. Arbuscular mycorrhizal fungi and glomalin-related soil protein as 
potential indicators of soil quality in a recuperation gradient of the Atlantic Forest in Brazil. Land Degradation \& Development, Chichester, v. 27, n. 2, p. 325-334, jun. 2016.

VINHAL-FREITAS, I. C. et al. Land use impact on microbial and biochemical indicators in agroecosystems of the Brazilian Cerrado. Vadose Zone Journal, Oregon, v. 12, n. 1, jan. 2013.

ZALBA, S. M.; CUEVAS, Y. A.; BOÓ, R. M. Invasion of Pinus halepensis Mill. following a wildfire in an Argentine grassland nature reserve. Journal of Environmental Management, London, v. 88, n. 3, p. 539-546, aug. 2008.

ZANINETTI, R. A.; MOREIRA, A.; MORAES, L. A. C. Physical, chemical, and biological attributes of a Xanthic Oxisol after forest conversion to rubber tree plantation in the Amazon. Pesquisa Agropecuária Brasileira, Brasília, v. 51, n. 9, p. 1061-1068, set. 2016.

ZILLER, S. R. A Estepe gramíneo-lenhosa no segundo planalto do Paraná: diagnóstico ambiental com ênfase a contaminação biológica. 2000. 177 f. Tese (Doutorado) - Universidade Federal do Paraná, Curitiba, 2000.

WATZLAWICK, L. F. et al. Fixação de carbono em floresta ombrófila mista em diferentes estágios de regeneração. In: SANQUETTA, C. R. et al. (Ed.). As Florestas e o carbono. Curitiba: Imprensa Universitária da UFPR, 2002. p. 153-173. 